\title{
Effectiveness of Four Lytic Phages Against Biofilm-Producing and Multidrug-Resistant Escherichia Coli
}

\author{
A.A.Abou Zeid ${ }^{1}$, M.A.Swelim ${ }^{2}$, F.M.Reda ${ }^{1}$, A.M.Abd El Haveez ${ }^{2}$ and M.A.Nasr-Eldin ${ }^{2}$ \\ ${ }^{1}$ Botany and Microbiology Dept., Faculty of Science, Zagazig Univ., Zagazig, Egypt \\ ${ }^{2}$ Botany and Microbiology Dept., Faculty of Science, Benha Univ, Benha, Egypt \\ E-Mail: nasreldeen.m@gmail.com
}

\begin{abstract}
Multi-drug-resistant (MDR) strains of biofilm-producing Escherichia coli are being reported worldwide and are threatening the health of human beings. These species are seen as the highest priority for the development of new phage biocontrol agents. Therefore, we isolated and characterized new and effective lytic phages as biocontrol agents against MDR E. coli. Bacteriophages (phages) were isolated from different wastewater samples, whilst E. coli strain was isolated from Sausage with accession number MN493640; it was resistant to $66.6 \%$ of tested common antibiotics with strong biofilm production. Phages designated $\Phi E \mathrm{Ecp} 1, \Phi \mathrm{Ecp} 2, \Phi \mathrm{Ecp} 3, \Phi E \mathrm{Ecp} 4$ and they were classified as being in the order Caudovirales, $\Phi E \mathrm{Ep} 1$ and $\Phi E \mathrm{E} 22$ belong to families Siphoviridae and Myoviridae respectively while $\Phi$ Ecp3, $\Phi$ Ecp4 belonging to family Podoviridae. The four phages and its cocktail showed polyvalent infectivity. All phages are stable at $\mathrm{pH}$ values range from 7-9; exhibited remarkable temperature stability $\left(55-65^{\circ} \mathrm{C}\right)$. They were stable in different concentrations of sodium chloride and did not lose their infectivity after exposure to Ultraviolet (UV) radiation for $30 \mathrm{~min}$. One-step growth curve analysis showed short latent period $(10 \mathrm{~min})$ and large burst sizes $(295,117,102$.and $127 \mathrm{PFU} / \mathrm{mL})$

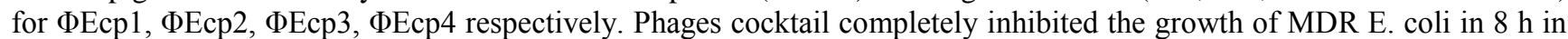
vitro and also significantly $(\mathrm{p}<0.05)$ eradicated the development of $24 \mathrm{~h}$ old biofilms. This study suggests that these four new phages can be characterized even farther as antimicrobial agents against biofilm-producing MDR E. coli.
\end{abstract}

Keywords: Multi-drug-resistant (MDR), Escherichia coli, Bacteriophages, Biocontrol, Biofilm.

\section{Introduction}

A variety in $E$. coli pathotypes causes enteric infections to spread via food or water to the host [1]. And certain groups are permanent or temporary intestinal microbiota participants. The daily existence of these strains suggests fecal contamination and poor hygiene and sanitation. Some of them, i.e. the pathogenic extraintestinal E. coli (ExPEC), once removed from the intestine, may cause serious infections outside the stomach [2], [3]. Furthermore, their natural habitat is also the gut and these pathogens usually reach the microorganism through food [4].

Some FBD-associated pathogenic bacteria may bind and form biofilms on a variety of materials like glass, plastics, steel, wood and foods and almost all food processing plants in nearly all circumstances [5]. Pathogenic E. coli has been reported for forming biofilms that lead to their pathogenicity [6].

Most of pathogenic bacteria have become multi-drug resistant to antibiotics [7]. Moreover, new antibiotics are not being produced at a sufficient rate to replace the previous medicines which are less effective [8]. The financial cost of resistance to antibiotics is constantly on the increase and now in the US alone approaches $\$ 55$ billion per year [9]. In comparison, the potential costs of future drug resistance growth remain unknown. Accordingly, adequate treatment and contribution to programs to combat antibiotic resistant bacteria is one of the main goals of modern medicine [7].

Bacteriophages are obligate intracellular bacterial parasites, have promising characteristics to control pathogens associated with foodborne illnesses and are deemed efficient to prevent the creation of biofilms and the dispersal of mature biofilms. Bacteriophage applications used in food protection and therapy strategies [10], [11].

Bacteriophages are commonly used to manage pathogens; however, high specificity may cause problems with their host selection. Subtypes of pathogens that must be regulated within each category are necessary so that an efficient bacteriophage does not have a very limited or extremely large variety of hosts. One approach is to address this constraint in the development of a bacteriophages mixture in order to increase the spectrum of lytic serovar interaction, like Salmonella. Such have also shown their effectiveness in suppressing other pathogens, such as E. coli $\mathrm{O} 157: \mathrm{H} 7$ in the treatment of poultry and phage therapy [12], [13]. Remarkably, multiple bacteriophages attacking E. coli O157:H7 have recently been recognized by the FDA as Safe (GRAS) and widely are used to improve the safety of various foods, particularly ready-to-eat items, by the United States food industry [14], [15]. The main objective of this study was to isolate and evaluate the efficacy of lytic phages to control MDR E. coli and their biofilms isolated from food samples.

\section{Material and methods}

\subsection{Collection of food samples}

Samples from different food products (meat, chicken, sausage, hamburger, Kareish cheese and fresh milk) used for pathogenic bacteria isolation randomly collected from various markets in Zagazig City, EL-Sharkia Governorate, Egypt [16]. 


\subsection{Isolation of pathogenic bacterial isolates}

Twenty five grams of each food sample were taken under aseptic conditions and good hygiene by the help of a sterile forceps and scissors, the sample was cut into small pieces. The food samples were homogenized and suspended in sterile peptone water and incubated at $37^{\circ} \mathrm{C}$ for $3 \mathrm{~h}$. Further, loopful inoculate of prepared food samples were streaked on the surface of specific media (Nutrient agar and, MacConkey's agar media). Plates were incubated at $37^{\circ} \mathrm{C}$ for $24 \mathrm{~h}$. For milk samples, isolation was done by using serial dilution method [17]. Serial dilutions of milk samples were prepared and then sample from different dilutions were spread over the Nutrient agar and, MacConkey's agar media. Plates were then incubated for $24 \mathrm{~h}$ at $37^{\circ} \mathrm{C}$. After incubation isolated colonies were restreaked on MacConkey's agar plate and pure cultures were isolated.

\subsection{Qualitative determination of biofilm formation \\ 2.4 Congo red agar method}

Biofilm formation was detected by Congo Red agar (CRA) method [18], [19]. Thirty five bacterial isolate from different food sources were cultured on the Brain heart infusion (BHI) broth (DIFCO®) with the addition of $0.08 \%$ Congo red supplemented with $5 \%$ sucrose. The bacterial isolates were streaked on BHI agar medium and incubated at $37^{\circ} \mathrm{C}$ for $24 \mathrm{~h}$. After incubation, black colonies with a dry crystalline consistency indicated biofilm production, whereas non-biofilm producers appear red.

\subsection{Microtiter plate method}

Biofilm formation was examined using 96 well flat bottom tissue culture plates [20], [21]. Overnight bacterial suspensions made in BHI broth with $1 \%$ glucose and the culture was further diluted 1:100 with fresh medium to mid-log phase $(\mathrm{A} 600=0.1)\left(10^{6}\right.$ cells $)$. $200 \mu \mathrm{L}$ of bacterial suspension was then inoculated and incubated overnight at a temperature of $37^{\circ} \mathrm{C}$ during 48 $\mathrm{h}$. The plates wells were carefully vacuumed during incubation and cleaned with a $200 \mu \mathrm{L} 1 \mathrm{X}$ saline phosphate saline (PBS) (pH 7.2). Biofilms that were still bound to the walls and bodies of the wells were sealed at room temperature with $2 \%$ sodium acetate and staining $2 \%$ crystal violet. Excess stain washed with deionized water and plate was completely dried. With micro ELISA auto reader (model), optical densities (OD at 570 $\mathrm{nm}$ ) were determined at Faculty of Pharmacy, Zagazig Univ. Biofilm assays were done in triplicate for each bacterial strain tested, and their mean absorbance values were determined and distinguished them as strong (> 0.24 ), moderate ( 0.12 to 0.24 ), and no biofilm formers (< 0.12 ) based on their O.D values at $570 \mathrm{~nm}$ [22], [23].

\subsection{Identification of selected bacteria}

The identification of the selected isolate based on strongest biofilm formation was characterized morphologically and biochemically according to Bergeys Manual of Systematic Bacteriology [24], then the isolate was molecularly confirmed based on amplification of
16S rRNA gene fragments through PCR. Then, the fragments were sequenced. The nucleotide sequence of amplified gene was subjected to BLAST analysis (National Center for Biotechnology Information) for bacterial identification and submitted to GenBank (https://www.ncbi.nlm.nih.gov/genbank/) and registered under accession number MN493640.

\subsection{Antibiotic sensitivity test}

To evaluate the resistance of strongest biofilm producer E. coli strain to different antibiotics, antibiotic sensitivity was performed on Mueller Hinton Agar by disc diffusion method [25]. Eighteen different antibiotics belonged to nine different antibiotic classes was placed onto the surface of seed plate agar and incubated for $24 \mathrm{~h}$ at $37^{\circ} \mathrm{C}$ (Table 1). The antibiotic resistance and susceptibility is tested in line with CLSI / NCCLS level [26].

\subsection{Isolation and purification of $E$. coli bacteriophages}

Phages were isolated from different sources (Zagazig University hospital wastewater, Agricultural drainage water, Sewage water); phages were detected in wastewater by spot test and plaque assay [27] using E. coli as a host. In brief, a $20 \mathrm{~mL}$ sample of wastewater from each different sample source was centrifuged for 20 minutes at $2000 \mathrm{rpm}$. The supernatant was filtered through sterile membrane filters $(0.22 \mu \mathrm{m})$ to eliminate bacterial load. The $100 \mathrm{~mL}$ Luria-Bertani (LB) broth of mixed bacterial culture was inoculated with $5 \mathrm{~mL}$ of each screened sample and incubated at $37^{\circ} \mathrm{C}$ for enrichment of phages. Centrifugation of bacterial cells was achieved at $5000 \mathrm{rpm}$ for $15 \mathrm{~min}$; the supernatant was purified via a $0.22 \mu \mathrm{m}$ membrane filter. With spot test, $3 \mathrm{ml}$ of top LB soft agar, $300 \mu \mathrm{L}$ fresh suspension of E. coli inoculated, has been overlayed on the LB pre-solidified plate. Once the top soft agar had been dry, $10 \mu \mathrm{L}$ of phage lysates were spotted on the plate. For the presence of transparent zones caused by phages, the plate was incubated at $37^{\circ} \mathrm{C}$ for 24 hours. For plaque assay method, the filtered sample $(500 \mu \mathrm{L})$ was mixed with $500 \mu \mathrm{L}$ of E. coli and mixed with the melted LB agar then poured onto petriplates. The phage plaques collected were screened by repeated single plaque isolation in order to ensure that only one form of bacteriophages was present. To generate adequate amounts of bacteriophages for the experiment, the protocol used for enrichment of phages including overnight growth of phages with their host bacteria then centrifugation and purification with 0.22 $\mu \mathrm{m}$ sterile membrane filter (Millex GP, Merck Millipore, Darmstadt, Germany). This method was used for all four bacteriophages. The bacteriophages ' titer and optimum infection multiplicity (MOI) were calculated using the above-mentioned plaque assay method.

\subsection{Morphological characterization of isolated phages}

The phage particles were examined at various magnifications with transmission electron microscope (TEM) (JEOLJEM, 2100, Japan) at Mansoura 
University, Mansoura, Egypt to determine morphology and their sizes.

\subsection{Physical characterization of isolated phages}

The influence of temperature, $\mathrm{pH}$, salinity and UV on four phages $\left(10^{11}\right.$ p.f.u $\left./ \mathrm{ml}\right)$ with lytic activity on $E$. coli has been checked. Phage suspensions in $1.5 \mathrm{ml}$ Eppendorf tubes were screened for phage stability assessment under different temperature environments, and tubes were incubated.at $37,40,45,55,65,75,85^{\circ} \mathrm{C}$ for $10 \mathrm{~min}$ [28].For their susceptibilities to different $\mathrm{pH}$ conditions, the phages suspensions were incubated at $37^{\circ} \mathrm{C}$ for $24 \mathrm{~h}$ at different $\mathrm{pH}$ values using $0.1 \mathrm{~N} \mathrm{HCL}$ and /or $0.1 \mathrm{~N} \mathrm{NaOH}$ (i.e. 3, 5, 7, 9 and 11) according to Pajunen et al [29]. Phages susceptibility to six sodium chloride concentration $(1,5,10,15,20$ and 30\%) was also determined. Phages susceptibility UV-light radiation $(254 \mathrm{~nm}, 70 \mu \mathrm{W} / \mathrm{cm} 2)$ at distance $15 \mathrm{~cm}$ in an uncovered a small plate from lamp was used as a UV source for the following times: 5, 10, 15, 20, 25 and $30 \mathrm{~min}$ [28].

\subsection{Host range of isolated phages}

The isolated phages were tested for the specificity of the host range against 12 different bacteria including $7 \mathrm{E}$. coli isolates, Bacillus cerus, Klebsiella pneumoniae, Proteus mirabilis, Staph. aureus and Staph. vitulinus according to Lee et al [30]. Briefly, on the pre-solidified nutrient plate, $3 \mathrm{ml}$ of top nutrient soft agar inoculated with $100 \mu \mathrm{L}$ of fresh suspension of each bacteria examined was overlaid. $10 \mu \mathrm{L}$ of each bacteriophage was spotted on the plate after top soft agar was dry. The phage cocktail host variety also is checked by spot-test for 12 specific bacterial strains. The plates were incubated for lysis zone formation overnight at $37^{\circ} \mathrm{C}$.

\subsection{One step growth curve}

One-step growth experiment was used for determination of burst size and latent period for the selected phages with some modification from that described early by Delbruck [31] Phage was added to its host bacterium by an M.O.I of approximately 1 PFU / $\mathrm{CFU} / \mathrm{ml}$ (optimal MOI), and incubated for $30 \mathrm{~min}$. into the water bath at $37^{\circ} \mathrm{C}$. The mixture was then centrifuged at $4^{\circ} \mathrm{C}$ for $4000 \mathrm{rpm}$ for $10 \mathrm{~min} .100 \mu \mathrm{L}$ of the host bacterium was added to this mixture, with $3 \mathrm{ml}$ of overlay medium poured into LB plates to determine the degree to which the phage is adsorbed in bacterial cells. After 5 minutes, $100 \mu \mathrm{L}$ was transferred to a $9.9 \mathrm{ml}$ tube of fresh $\mathrm{LB}$, then $1 \mathrm{ml}$ from this tube to $9 \mathrm{ml} \mathrm{LB}$, and before moving the tube to another tube containing $9 \mathrm{ml}$ $\mathrm{LB}$, the tube was gently shaken. The three tubes were incubated at $37^{\circ} \mathrm{C}$ in a water bath. Planning to start 7 minutes after phage was added to the host and at intervals of 5 minutes for $90 \mathrm{~min}$; the diluted suspension was plated by removing $100 \mu \mathrm{L}$ of the suspension and adding $200 \mu \mathrm{L}$ of $E$. coli and $3 \mathrm{ml}$ of overlay media. The mixture was mixed and poured onto LB agar plates. During $24 \mathrm{~h}$ of incubation, the number of plaques was estimated at $37^{\circ} \mathrm{C}$. The relative burst size was determined. The experiments for each phage were repeated three times.

\subsection{Effect of phages and its cocktail on plankton culture of $E$. coli}

The effect of each phage and a mixture of them at an multiplicity of infection (M.O.I) of 1 on the growth of MDR E. coli strain $\left(10^{8}\right.$ cells $)$ in liquid medium were detected over time from 0 to $24 \mathrm{~h}$ using optical density measurement at (OD $600 \mathrm{~nm}$ ) according to Elhalag et al [32]. The experiment was repeated three times.

\subsection{Determination of phages activity and its cocktail on biofilm formation of $E$. coli}

Microtiter plate assay [33] was used to study the effect of phages and its cocktail on biofilm production of E. coli. E. coli was diluted with liquid broth by 1:100 and poured onto untreated 96-well flat bottomed polystyrene plate (Costar; Corning Inc., Corning, NY, USA). The plate was incubated at $37^{\circ} \mathrm{C}$ and shaken. Biofilm may be generated within $24 \mathrm{~h}$ to order to remove planktonic cells, per biofilm washed twice in 0.9 percent $\mathrm{NaCl}$. Then phages have been diluted by 0.9 percent $\mathrm{NaCl}$ and applied to a variety of wells at different M.O.I (each phage at M.O.I 0.01, 0.1 and 1) and the mixture phages in other wells, whilst other wells have been introduced to the normal saline as a negative control. Plate was incubated at $37^{\circ} \mathrm{C}$ for $24 \mathrm{~h}$ and continuously shaked at $130 \mathrm{rpm}$.

The biofilm washed twice with 0.9 percent $\mathrm{NaCl}$ and the overall biomass was calculated by the previously mentioned crystal violet stain. Briefly, the biofilms were often washed with a Nacl solution of $0.9 \%$, dried inverted and dyed with a crystal violet of $1 \%$ for $20 \mathrm{~min}$. The plates have been washed with water and air-dried. Each well was filled with $200 \mu \mathrm{L} 0.9$ percent $\mathrm{NaCl}$ solution and O.D. measured in an ELISA plate reader at $570 \mathrm{~nm}$ [34]. The experiments were performed in triplicate.

\subsection{Statistical Analysis}

The results are interpreted as the mean \pm standard mean division (SDM). The data were statistically evaluated using variance study (one-way ANOVA), and then the Duncan multi-comparison study. The statistical significance was considered at $\mathrm{P}<0.05$. Statistical Package for Social Sciences (SPSS) for Windows version 20 software was used.

\section{Results}

\subsection{Isolation of pathogenic bacterial isolates from different food Samples}

Thirty five bacterial isolates were isolated from different food sources (Meat, Chicken, Sausage, Hamburger, Kareish cheese and fresh milk). The result showed that the pathogenic bacteria isolated from meat, chicken, sausage, hamburger, quraish cheese and fresh milk had percentages of $20 \%, 14.3 \%, 14.3 \%, 20 \%$, $17.1 \%$ and $14.3 \%$ respectively. These results indicated that the higher percentages of pathogenic bacteria were 
represented from meat and hamburger followed by quraish cheese.

\subsection{Screening of bacterial isolates for biofilm formation}

The biofilm formation of all isolates was assessed using Congo Red Agar plates (CRA) and Tissue Cultures Plate (TCP) methods using microtiter plate for quantification of biofilm formation after the crystal violet staining. Seventeen pathogenic isolate gave black colonies on CRA plate with percentage $48.6 \%$. The isolate code No S16 was selected as the most biofilm producer isolate with OD 0.259 .

\subsection{Bacterial identification}

Morphological characterization showed dry, donutshaped colonies with a dark pink color and is surrounded by precipitated bile salts with a dark pink patch. Bacterial isolate was confirmed to be Gram-negative bacilli by using Gram staining technique. The identification of the selected bacterial isolate (S16) was confirmed by using $16 \mathrm{~S}$ rRNA gene sequencing as E. coli, then sequence was submitted to GenBank and registered under accession number MN493640. Blast search indicate that the selected isolates showed 97.46 identities with the deposited isolates of E. coli.

\subsection{Antibiotic resistance profile of isolated $E$. coli S16}

The susceptibility of biofilm producing E. coli S16 strain to different classes of antibiotics was determined by measuring the diameter of inhibition zones $(\mathrm{mm})$. Isolated E. coli S16 showed $66.6 \%(12 / 18)$ resistant to antibacterial agents (antibiotics) Table (1). E. coli S16 resistant to Ampicillin/Sulbactam (SAM) 10/10 $\mu \mathrm{g}$, Amoxicillin/Clavulanic acid (AMC) 20/10 $\mu \mathrm{g}$, Amoxicillin (AX) $10 \mu \mathrm{g}$, Ceftizoxime (ZOX) $30 \mu \mathrm{g}$, Cefoperazone/Sulbactam (CES) 75/30 $\mu \mathrm{g}$, Cefoperazone (CFP) $75 \mu \mathrm{g}$, Ceftriaxone (CRO) $30 \mu \mathrm{g}$, Gentamicin (CN) $10 \mu \mathrm{g}$, Vancomycin (VA) $30 \mu \mathrm{g}$, Erythromycin (E) $15 \mu \mathrm{g}$, Azithromycin (AZM) $15 \mu \mathrm{g}$ and Doxycycline (DO) $30 \mu \mathrm{g}$.

\subsection{Bacteriophage isolation}

Four phages were isolated from 25 different collected wastewater samples by spot and plaque assays. Bacteriophages were selected based on E. coli S16 as an indicator host bacterium. Four different phage types were assigned on the basis of plaque morphology. The plaques formed were mostly circular and clear. There were four sizes of lysis plaques, $(5 \mathrm{~mm}),(3 \mathrm{~mm}),(2 \mathrm{~mm})$ and $(1.5$ $\mathrm{mm})$ visible on DAL plates from the environmental samples Table (2).

\subsection{Morphological analysis by transmission Electron Microscopy (TEM)}

According to the TEM analysis, four phage designated $\Phi E c p 1, \Phi E c p 2, \Phi E c p 3$ and ФEcp4 appeared with tail and $\Phi E c p 2$ has contractile tail. ФEcp1, ФEcp2, $\Phi E c p 3$, and $\Phi E c p 4$, has head with diameter 65.70, 44.48, 71.04, 68.43 respectively $\Phi E c p 1, \Phi E c p 2$, and $\Phi E c p 4$ has tail length $130.77,230.29$ and $17.58 \mathrm{~nm}$ respectively Fig (1). Phage $\Phi E c p 1$ was belonging to the Siphoviridae family; while phage $\Phi$ Ecp2 belong to the Myoviridae family which characterized by phages with contractile tail, the phages $\Phi$ Ecp 3 and $\Phi E c p 4$ were belong to the Podoviridae family Table (3).

\subsection{Physical properties of isolated bacteriophages}

Upon exposure to $55^{\circ} \mathrm{C}$, the four phages were still active for $10 \mathrm{~min}$, above this temperature the infectivity of $\Phi E c p 1$ and $\Phi E c p 2$ were still stable at $65^{\circ} \mathrm{C}$ but lost its viability at $70^{\circ} \mathrm{C}$ Fig (2). On the other hand, the infectivity of $\Phi \mathrm{Ecp} 3$, ФEcp4 phages was complete loss their infectivity after exposure to $65^{\circ} \mathrm{C}$ for $10 \mathrm{~min}$. All phages are still stable at $\mathrm{pH}$ values ranging from $7-9$. Where above or below that $\mathrm{pH}$ range, these phages infectivity has decreased at a high rate. The result indicated that all isolated phages maintained its viability under alkaline media with $\mathrm{pH}$ (9) also it could do this at neutral media at $\mathrm{pH}$ (7), But it could not maintain this viability in acidic media Fig (3). Phages remained fully active at all different concentration of $\mathrm{NaCl}(1,5,10,15$, 20 and $30 \%$ ) after $30 \mathrm{~min}$ of incubation Fig (4). E. coli phages did not lose their infectivity after exposure to UV radiation at $15 \mathrm{~cm}$ distance for $30 \mathrm{~min}$ Fig (5).

\subsection{Host range of isolated bacteriophages}

The host range of the isolated phages $\Phi E c p 1$, ФEcp2, ФEcp 3 and $\Phi E c p 4$ and also cocktail of them toward 12 different bacterial strains determined by spot test. Four different E. coli including strong biofilm producing strain E. coli S16, Bacillus cerus and Klebsiella pneumoniae were infected by four phages and their cocktail but they did not infect Staph. aureus, Staph. vitulanus, and Proteus mirabilis. As the result the isolated phages had a broad spectrum of lytic activity Table (4).

\subsection{One step growth curve}

The one-step growth curve helped to explain the growth kinetics of parameters such as latent period, raised and the bursting size of the bacteriophages in the study. Tests were conducted at $37^{\circ} \mathrm{C}$, with an average M.O.I of 1 for 4 phages. Data presented in Fig (6) indicated that the latent period for phages $\Phi E c p 1$, ФEcp2, ФEcp3 and ФEcp4 was found to be $10 \mathrm{~min}$ and the burst size was 295, 117, 102 .and $127 \mathrm{PFU} / \mathrm{mL}$ for ФEcp1, ФЕсp2, ФЕсp3, ФЕсp4 respectively.

\subsection{Lytic activity of isolated phages in plankton culture}

E. coli $\mathrm{S} 16$ was treated with M.O.I=1 of phages (ФEcp1, ФEcp2, ФEcp3 and ФEcp4) and its cocktail. The results revealed that the addition of all four phages completely inhibited the growth of MDR E. coli S16 in vitro but phages cocktail gave the fastest inhibition of bacterial culture after $8 \mathrm{~h}$ of challenge Fig (7). 
3.11 Influence of phages and its cocktail on biofilm formation of $E$. coli

To determine the action of four phages (ФEcp1, ФEcp2, ФEcp3, ФEcp4) and its cocktail on biofilms formation by $E$. coli $\mathrm{S} 16$, the biofilms-forming strain was grown in LB in microtiter plates for $24 \mathrm{~h}$. Thereafter, biofilms were challenged with separated phages at different M.O.I=1, 0.1 and 0.01 . Also cocktail of phages concentration was tested. The reduction in biomass of the biofilms compared with the control was evident. E. coli phages showed interesting results after $24 \mathrm{~h}$ of biofilms formation. The M.O.I of 1 for phages $\Phi E c p 1, \Phi E c p 2$, ФEcp3, ФEcp4 and its cocktail recorded the highest inhibition of biofilm formation $(75.28 \%, 77.6 \%, 78.76 \%$, $72.97 \%$ and $86.87 \%$ ) respectively of MDR E. coli $\mathrm{S} 16$ in all tested M.O.I, and phages cocktail had the highest percentage of inhibition compared by other phages Fig (8).

Table (1) Antibiotic resistance and susceptibility of E. coli .

\begin{tabular}{|c|c|c|c|}
\hline Antibiotic class & Antibiotic name & Disc content $(\mu \mathrm{g})$ & $\begin{array}{c}\text { Activity* } \\
\text { (R/I/S) }\end{array}$ \\
\hline \multirow{3}{*}{ Penicillins } & Ampicillin/Sulbactam (SAM) & $10 / 10$ & $0 / \mathrm{R}$ \\
\hline & Amoxicillin/Clavulanic acid (AMC) & $20 / 10$ & $0 / \mathrm{R}$ \\
\hline & Amoxicillin $(\mathrm{AX})$ & 10 & $0 / \mathrm{R}$ \\
\hline \multirow{4}{*}{ Cephalosporins } & Ceftizoxime $(\mathrm{ZOX})$ & 30 & $0 / \mathrm{R}$ \\
\hline & Cefoperazone/Sulbactam (CES) & $75 / 30$ & $0 / \mathrm{R}$ \\
\hline & Cefoperazone (CFP) & 75 & $0 / \mathrm{R}$ \\
\hline & Ceftriaxone (CRO) & 30 & $0 / \mathrm{R}$ \\
\hline \multirow{2}{*}{ Aminoglycosides } & Amikacin $(\mathrm{AK})$ & 30 & $22 / \mathrm{S}$ \\
\hline & Gentamicin $(\mathrm{CN})$ & 10 & $0 / \mathrm{R}$ \\
\hline Glycopeptides & Vancomycin (VA) & 30 & $0 / \mathrm{R}$ \\
\hline \multirow{2}{*}{ Macrolides } & Erythromycin (E) & 15 & $0 / \mathrm{R}$ \\
\hline & Azithromycin (AZM) & 15 & $0 / \mathrm{R}$ \\
\hline Tetracyclines & Doxycycline (DO) & 30 & $0 / \mathrm{R}$ \\
\hline \multirow{2}{*}{ Quinolones } & Nitrofurantoin $(\mathrm{F})$ & 300 & $30 / \mathrm{S}$ \\
\hline & Ciprofloxacin (CIP) & 5 & $30 / \mathrm{S}$ \\
\hline Sulfonamides & Trimethoprim-Sulfamethoxazole (SXT) & $1.2 / 23.7$ & $13 / \mathrm{I}$ \\
\hline \multirow{2}{*}{ Carbapenems } & Meropenem (MEM) & 10 & $25 / \mathrm{S}$ \\
\hline & Imipenem (IPM) & 10 & $34 / \mathrm{S}$ \\
\hline
\end{tabular}

$* \mathrm{R}=$ Resistant, $\mathrm{I}=$ Intermediate and $\mathrm{S}=$ Susceptible

Table (2) Isolation and plaque morphology of phages from different sources.

\begin{tabular}{lccc}
\hline Phage isolate & Source & $\begin{array}{c}\text { Plaque diameter } \\
(\mathbf{m m})\end{array}$ & Plaque morphology \\
\hline ФEcp1 & Agricultural drainage water & 5.0 & Large sized, Circular, Clear, without center \\
ФEcp2 & Agricultural drainage water & 3.0 & $\begin{array}{c}\text { Large sized, Circular, Clear, without center } \\
\text { Medium sized, Circular, Clear, without } \\
\text { center }\end{array}$ \\
ФEcp3 & Sewage water & 2.0 & $\begin{array}{c}\text { Medium sized, Circular, Clear, without } \\
\text { center }\end{array}$ \\
\hline
\end{tabular}

Table (3) Morphological properties, taxonomical position and titers of isolated phages.

\begin{tabular}{|c|c|c|c|c|}
\hline Phage name & Prospected Family & Head Diameter (nm) & Tail Length (nm) & Phage titer (PFU/mL) \\
\hline ФEсp1 & Siphoviridae & 65.70 & 130.77 & $1.2 \times 10^{11}$ \\
\hline ФЕср2 & Myoviridae & 44.48 & 216.62 & $6.2 \times 10^{11}$ \\
\hline ФЕср3 & Podoviridae & 71.04 & ND* & $6 \times 10^{11}$ \\
\hline ФЕср4 & Podoviridae & 68.43 & 17.58 & $5.3 \times 10^{11}$ \\
\hline
\end{tabular}

$* \mathrm{ND}=$ Not Detected.

Table (4) Host range of E. coli bacteriophages against different bacterial species.

\begin{tabular}{|c|c|c|c|c|c|c|}
\hline Bacterial isolate & Source & ФЕср1 & ФЕср2 & ФЕср3 & ФЕср4 & Phages Cocktail \\
\hline E. coli S16 & This study & + & + & + & + & + \\
\hline E. coli M & Zagazig University & + & + & + & + & + \\
\hline E .coli 10157 & Zagazig University & - & - & - & - & - \\
\hline
\end{tabular}




\begin{tabular}{|c|c|c|c|c|c|c|}
\hline Table (4) Continue & & & & & & \\
\hline E. coli & Zagazig University & - & - & - & - & - \\
\hline E. coli 0157 & Zagazig University & - & - & - & - & - \\
\hline E. coli S1 & Benha children's Hospital & + & + & + & + & + \\
\hline E. coli S2 & Benha children's Hospital & + & + & + & + & + \\
\hline Bacillus cerus & Zagazig University & + & + & + & + & + \\
\hline Klebsiella pneumonia & Zagazig University & + & + & + & + & + \\
\hline Proteus mirabilis & Zagazig University & - & - & - & - & - \\
\hline Staph. Aureus & Zagazig University & - & - & - & - & - \\
\hline Staph. Vitulinus & Zagazig University & - & - & - & - & - \\
\hline
\end{tabular}

(+ means lysis) (- means no lysis).
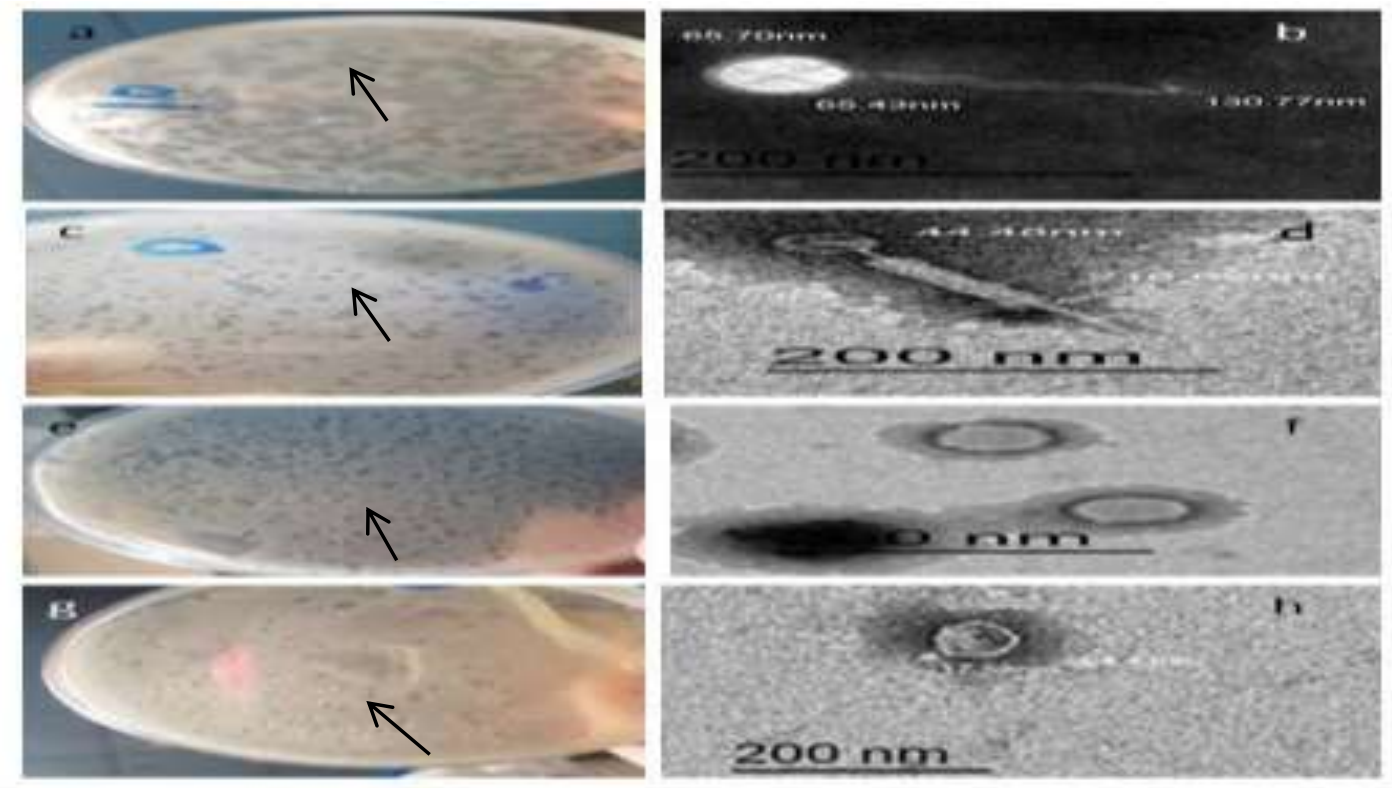

Fig (1) Plaques and morphological characterization of isolated phages (a, b) for $\Phi E c p 1,(c, d)$ for $\Phi E c p 2,(e, f)$ for $\Phi E c p 3$ and $(g, h)$ for $\Phi E c p 4$.

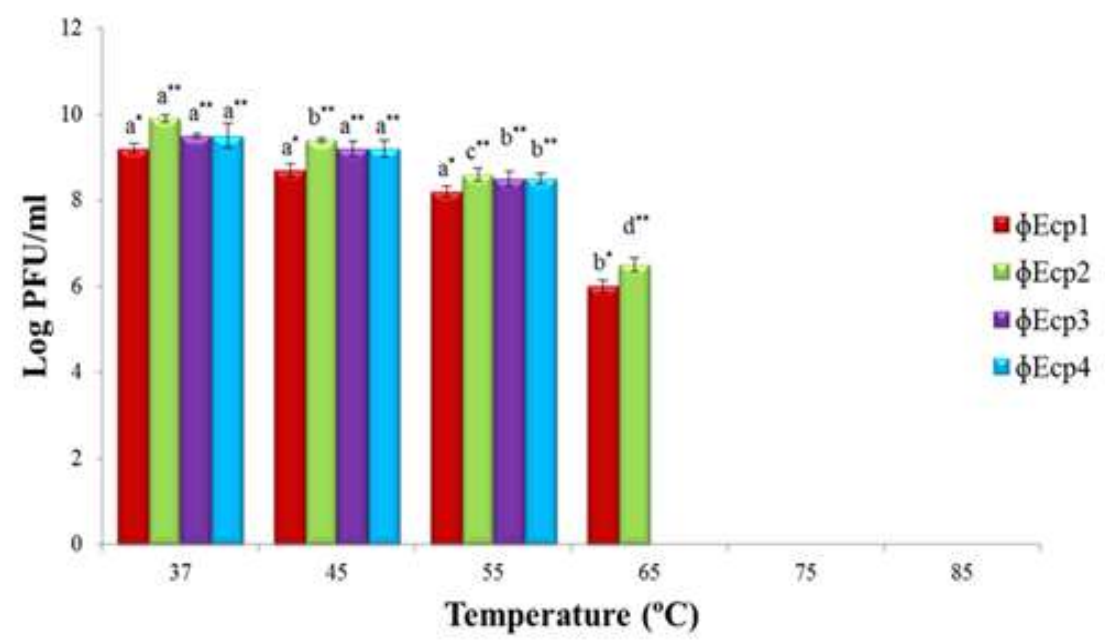

Fig (2) Effect of temperature on the infectivity of the isolated phages. Each experiment was performed in triplicate. $(*)$ Represents a significant difference between all groups using one-way A NOVA $(\mathrm{P} \leq 0.05)$.

$(* *)$ Represents a significant difference between all groups using one-way A NOVA $(\mathrm{P} \leq$ 0.001).Different letters indicate statistical differences at $\mathrm{P} \leq 0.05$ by Duncan's test. Standard bars are standard division of the means. 


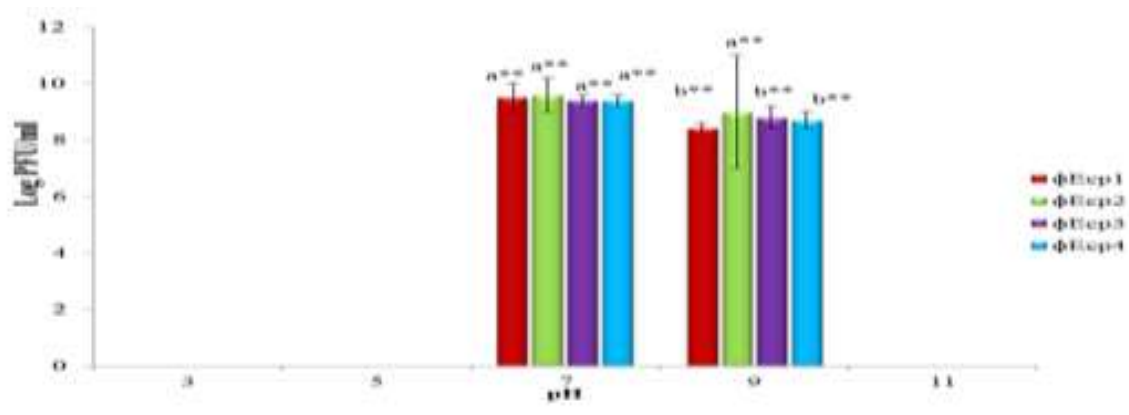

Fig (3) Effect of different $\mathrm{pH}$ values on the infectivity of the isolated phages. . Each experiment was performed in triplicate. (*) Represents a significant difference between all groups using one-way A NOVA $(\mathrm{P} \leq 0.05)$. (**)Represents a significant difference between all groups using one-way A NOVA $(\mathrm{P} \leq 0.001)$. Different letters indicate statistical differences at $\mathrm{P} \leq 0.05$ by Duncan's test. Standard bars are standard division of the means.

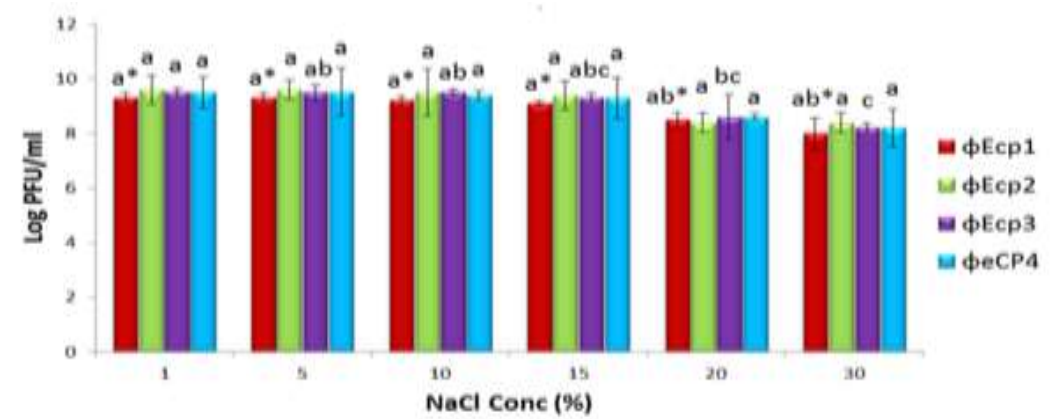

Fig (4) Effect of $\mathrm{NaCl}$ Conc on the infectivity of the isolated phages. Each experiment was performed in triplicate. (*)Represents a significant difference between all groups using one-way A NOVA $(\mathrm{P} \leq 0.05)$. $(* *)$ Represents a significant difference between all groups using one-way A NOVA $(\mathrm{P} \leq 0.001)$. Different letters indicate statistical differences at $\mathrm{P}$ $\leq 0.05$ by Duncan's test. Standard bars are standard division of the means.

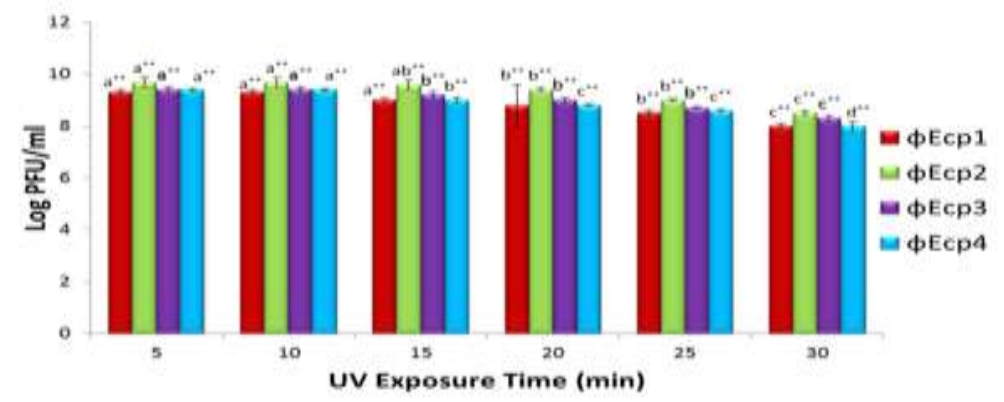

Fig (5) Effect of Ultraviolet irradiation on the infectivity of the isolated phages. Each experiment was performed in triplicate. (*) Represents a significant difference between all groups using one-way A NOVA ( $\mathrm{P} \leq$ 0.05). (**)Represents a significant difference between all groups using one-way A NOVA $(\mathrm{P} \leq 0.001)$.Different letters indicate statistical differences at $\mathrm{P} \leq 0.05$ by Duncan's test. Standard bars are standard division of the means. 

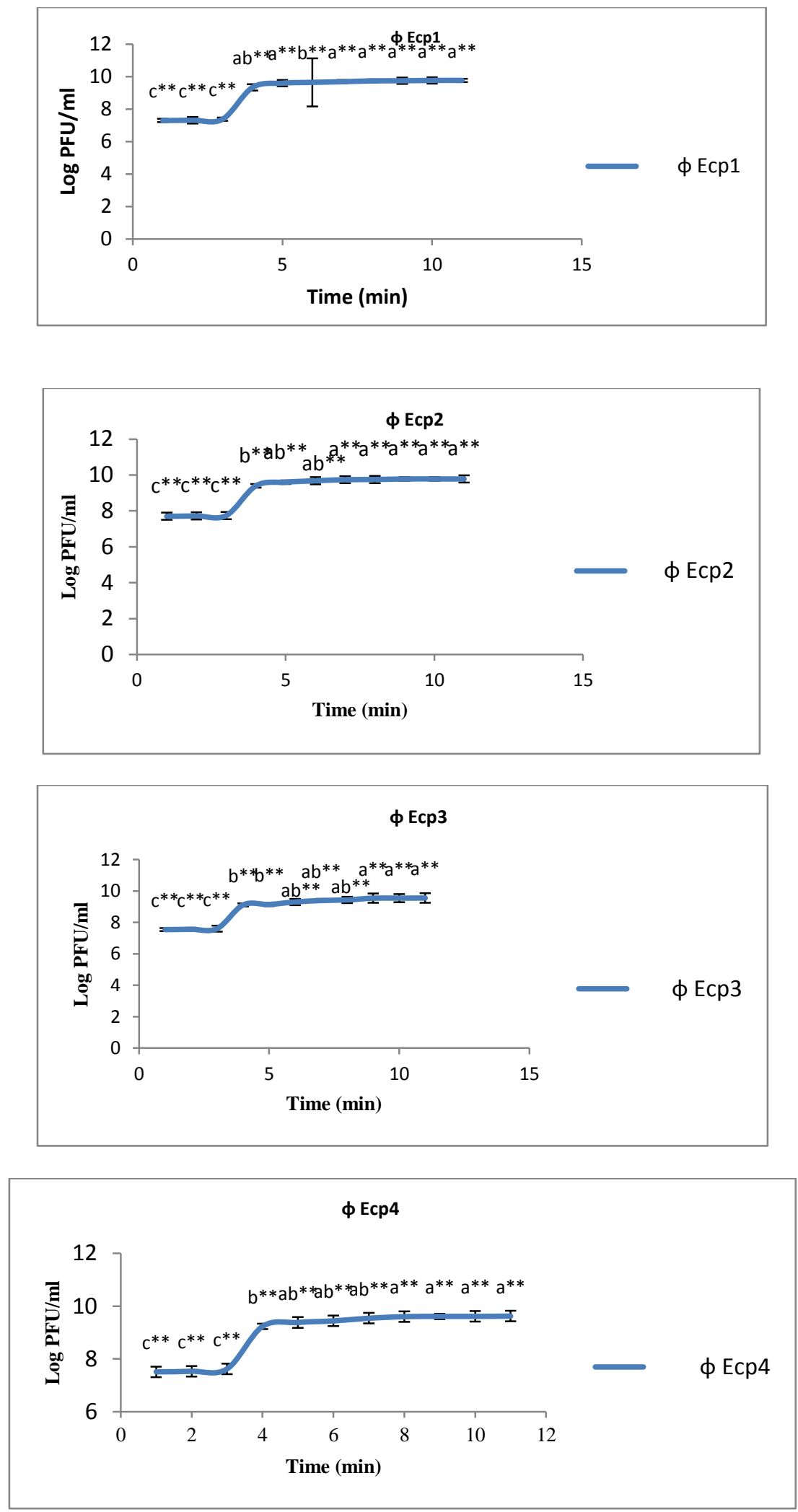

Fig (6) One step growth curve of isolated phages. Each experiment was performed in triplicate. (*)Represents a significant difference between all groups using one-way A NOVA ( $\mathrm{P} \leq 0.05)$. (**)Represents a significant difference between all groups using one-way A NOVA (P $\leq 0.001$ ). Different letters indicate statistical differences at $\mathrm{P} \leq 0.05$ by Duncan's test. Standard bars are standard division of the means.. 


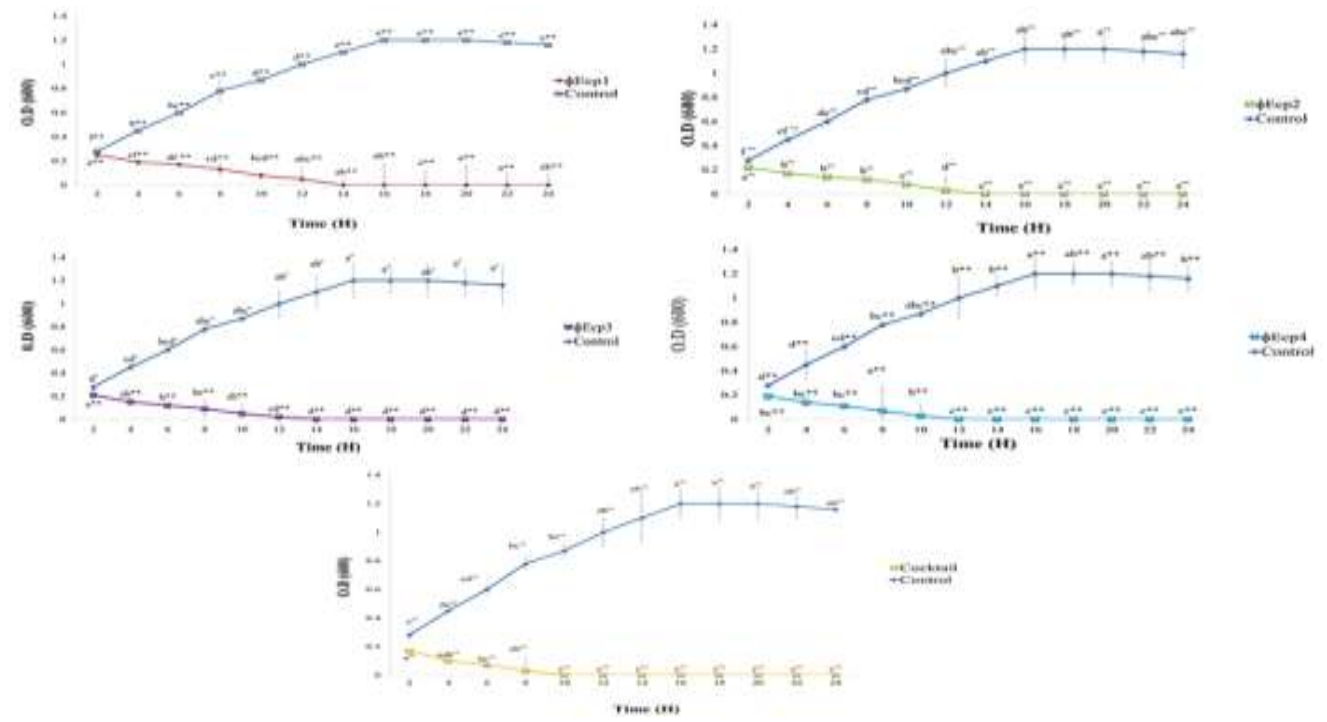

Fig (7) Effect of phages and its cocktail on growth curve of the host E.coli. (*)Represents a significant difference between treated and control (without phages) samples using one-way ANOVA $(\mathrm{P} \leq 0.05),(* *)$ Represents a significant difference between treated and control (without phages) samples using one-way ANOVA $(\mathrm{P} \leq 0.001)$.Different letters indicate statistical differences at $\mathrm{P} \leq 0.05$ by Duncan's test. Standard bars are standard division of the means.

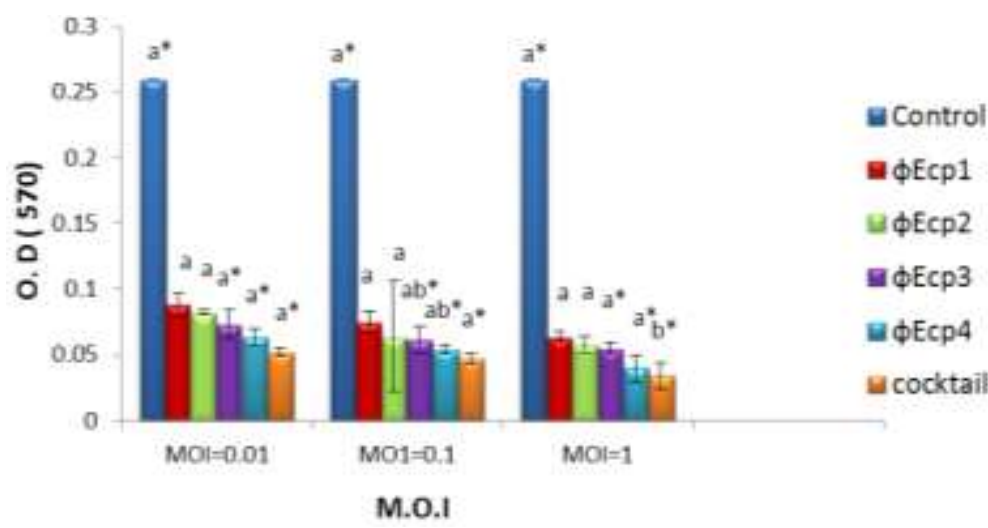

Fig (8) Reduction of E.coli biofim after $24 \mathrm{~h}$ of challenge with phages isolated and cocktail. (*)Represents a significant difference between all groups using one-way A NOVA (P $\leq 0.05)$. Different letters indicate statistical differences at $\mathrm{P} \leq 0.05$ by Duncan's test. Standard bars are standard division of the means.

\section{Discussion}

Restricted conventional antibiotic output has created severe problems in the treatment of infectious diseases. Intensive use of antibiotics for humans and animals may result in an increased pathogenic bacteria resistant community. There is therefore a recent increase in research focused on natural product biosynthesis [35].

The present study aimed to detect and characterize of novel strategies using natural products to control the persistence of pathogens as bacteriophages. Thirty five pathogenic bacterial isolates were isolated from different food sources. These results indicated that the high percentages of pathogenic bacteria were represented from meat and hamburger followed by kareesh cheese,
These results are in line with Gundogan et al [36] who reported that 175 out of 209 total Staphylococci $(83.7 \%)$ isolated from raw calf meat (minced), chicken drumsticks, raw milk, ice cream and white cheese samples were coagulase negative staphylococci and 34 $(16.3 \%)$ were coagulase-positive staphylococci.

Biofilm formation is a microorganism phenomenon which leads to a persistent microbial mass resistive to antimicrobial agents and is associated with approximately 80 percent of human bacterial infections. Infections from Staphylococcus sp. biofilms and Enterobacteria like E. coli are hard to diagnose and can lead to high healthcare costs and morbidity levels [37]. 
In the present study, all pathogenic bacterial isolates were screened for biofilm formation on screening medium, 17 pathogenic isolates gave black colonies on CRA plate with percentage $48.6 \%$. The isolate code S16 was selected as the most biofilm producer isolate with OD 0.259 [38].

In the current study, one bacterial isolate (S16) was selected as highest biofilm producer. This isolate was characterized morphologically and biochemically according to Bergeys Manual of Systematic Bacteriology [24] as members of genus E. coli. The identification of the selected isolate was molecularly confirmed based on $16 \mathrm{~S}$ rRNA gene sequences. The nucleotide sequences of amplified gene have been deposited under accession number MN493640. Blast search indicate that the selected isolates showed $97.46 \%$ identities with the deposited isolates of $E$. coli. Multidrug-resistant prevalence $E$. coli strains are increasing globally mainly due to the spread of mobile genetic elements, such as plasmids [39], [40].

E. coli had high tetracycline, amoxicillin and sulfameth-oxazole resistances $(63.1 \%-76.1 \%)$ [41] and our study illustrated that $E$. coli $\mathrm{S} 16$ had high penicillins, cephalosporins, glycopeptides, macrolides and tetracyclines classes resistances $(100 \%)$ but it was susceptible to quinolones and carbapenems.

Bacteriophages were developed as tools for controlling a variety of pathogenic bacteria in the food. New approaches for biofilm control were therefore discussed, including the use of enzymes, bacteriophages, microbial interactions and metabolic molecules as possible biological strategies [42]. Recently, concern in the use of bacteriophages as potential candidates for biofilms assault has increase [43], [44]. Bacteriophages are bacterial parasites have the promising characteristics for controlling FBD-related pathogens and are seen as successful in inhibiting the development of the biofilm and its dispersion. We offer a more natural approach to health and food security compared to traditional approaches [10].

Bacteriophages under study were isolated from different wastewater samples. E. coli phages are usually isolated from sewage, wastewater in hospitals, polluted rivers and human or animal fecal samples [45].

The spot test was used to detect phages in the environment samples and confirmed with double agar layer (DAL) method, using exponential cultures of $E$. coli $\mathrm{S} 16$ as the host bacterium this method is widely used in bacteriophages isolation [46].

The formation of plaques on the DAL plates was evidence of the presence of active bacteriophages in the sample, plaques of four sizes categorized as medium and large, high titer stock of phages were prepared by using soft agar layers of the confluently lysed double plates the lysates obtained constantly have phage titers up to $10^{11}$ p.f.u/ml. Electron microscope of negatively stained phages showed that four phages belong to three different families, phage $\Phi E c p 1$ belong to Siphoviridae, $\Phi E \mathrm{Ep} 2$ belong to Myoviridae and the other two phages (ФEcp3and ФEcp4) belong to Podoviridae family [47].
Bacteriophages that are used in phage therapy should be resistance to temperature and stable at wide $\mathrm{pH}$ range [48]. Temperature susceptibility of phages in present finding is in conformity to those reported by Shende et al [49] they found that EHR1, EHR2, and EHR3 isolates were inactivated when exposed to $70^{\circ} \mathrm{C}$ for $3 \mathrm{~min}$. These phages are stable at acidic and neutral $\mathrm{pH}$ present finding are near to reports by Shende et al [49] and Shukla and Hirpurkar [50] who found that optimum phage viability was between $\mathrm{pH} 5$ and 9 , and that all phages were completely inactivated at $\mathrm{pH} 3$ and 11 . Low $\mathrm{pH}$ influences the phage aggregation and decreases their entry into the host cells [51]. In this study, phages titer was unchanging within solutions containing different sodium chloride concentrations. This indicates that the phages resist the high concentration of salt [52] successfully obtained bacteriophages from a soil sample of salt plains in United States.

The four phages did not lose its infectivity after exposure to UV irradiation for $30 \mathrm{~min}$, on the contrary Ramirez et al [53] found that non encapsulated bacteriophages completely inactivated after $30 \mathrm{~min}$ of exposing time to UV light and also, Jaiswal and Dhar [54] who found that the ultraviolet sensitivity of all four phages (LRPI-1, LRP-4, LRP-13, andLRPI-15) showed a linear exponential killing. Ultraviolet radiation is known to cause the biological inactivation of virus particles and one way to look at phages under stressful condition.

So, our results proved that the isolated phages (ФEcp1, ФEcp2, ФEcp3and ФEcp4) were stable under adverse conditions like UV irradiation, thermal conditions and different $\mathrm{pH}$ values. Considering these advantages of recorded biological parameter and physical stability, the isolated phage may be good potential therapeutic agents in phage therapy or in food industry. Host range is an important characteristic factor, which makes the bacteriophages a potential agent against bacterial infection [55], [56].

The host range influenced by a combination of factors, including the specificity of phages hosting binding proteins, biochemical interactions during infection, the existence of related prophages, and different plasmids (especially for phages adsorbed by pili) and bacterial phage resistance mechanisms must be identified [56], [57].

Results indicated that, the isolated phages showed polyvalent infectivity and have broad host range. The preparation of phage cocktail may be more successful for infect a broader range of $E$. coli as a biocontrol agents. The phage cocktail seemed to have a broad host range. Also it was able to infect three species of bacteria [58], [59], [60]. The phage cocktail also was able to infect different strains of the same species E. coli.

The impact of variations in the physical and chemical environment on the length of the infectious process and on virus yield per infected host cell can be calculated quite clearly by one step in growth experiments .One step growth experiments can also be used to assess the duration of the length of the phage eclipse, latent, growing and burst times [56]. A phage with both a short 
latent period (10 min or less) and a large brust size (>50 PFU/ $\mathrm{mL}$ ) may have a selective advantage over competing phages, resulting in very high lytic activity [61]. In this study the four phages have short latent periods (10 $\mathrm{min})$ and large burst sizes thus becoming good candidates in phage bio-control agents. Phage therapy only needs to reduce the density of infecting bacteria to level at which the immune system can take care of the remaining bacteria [62]. In this study, the potential of isolated phages in reduction of bacterial population size in liquid culture was determined over time from 0 to $24 \mathrm{~h}$. Data showed a quick lysing of host cells after treatment with each phage and phage cocktail and completely inhibited after (8h). In agreement with our study, a previous study demonstrated that bacteriophage JBP901 could control B. cereus in 3h [63] the fastest inhibition of $B$. cereus appeared with phage cocktail. In order to prevent the emergence of phage resistance bacteria, a cocktail of broad host range phages was recommended for the application of bacteriophages in the food industry [64].

In this study, the isolated new 4 phages ( $\Phi E c p 1$, ФEcp2, ФEcp3and ФEcp4) and its cocktail caused strong biomass reduction of MDR E. coli biofilm, where phages cocktail gave the highest biofilm inhibition up to $86.87 \%$. Bacteriophage has ability to increase in number during the infection process, make phage excellent potential diagnostic and therapeutic agent for fight against bacterial disease [65].

\section{Conclusion}

According to the results of this study, the isolated phages and its cocktail had polyvalent infectivity with strong lytic activity against of MDR E. coli. In addition, the biofilm infection study shows that phages could have a successful technique to counter virulent biofilms with great eradication in the biofilm matrix of MDR pathogens, so that, these phages will be used as safe effective control strategies for biofilm producing foodborne pathogens.

\section{Acknowledgements Not applicable. \\ I- Conflict of interest}

No potential conflict of interest was reported by the authors.

\section{II-Ethical approval}

This article does not contain any studies with human participants or animals performed by any of the authors.

\section{III-Funding}

This research did not receive any specific grant from funding agencies in the public, commercial, or not-forprofit sectors.

\section{IV-Data Availability}

All datasets generated or analyzed during this study are included in the manuscript.

\section{References}

[1] G. Newell, M .Koopmans, L .Verhoef, E. Duizer, A. Aidara-Kane, H.Sprong, Food-borne diseases -The challenges of 20 years ago still persist while new ones continue to emerge. Int $\mathrm{J}$ Food Microbiol, Vol.139, PP.3-15,2010.

[2] R.M. Vejborg, P.Klemm ,Cellular chain formation in Escherichia coli biofilms. Microbiology;vol. 155(5), PP.1407-1417,2009.

[3] C.D.Köhler, U.Dobrindt, What defines extraintestinal pathogenic Escherichia coli? Int. J. Med. Microbiol;vol. 301(8),pp.642-647,2011.

[4] R.Capita, F. Riesco-Peláez, A .Alonso-Hernando, C. Alonso-Calleja ,Exposure of Escherichia coli ATCC 12806 to sublethal concentrations of food-grade biocides influences its ability to form biofilm, resistance to antimicrobials, and ultrastructure. Appl. Environ. Microbiol, Vol.80(4), PP.1268-1280,2014.

[5] L.K.Winkelstroter, F.B. Teixeira, E.P. Silva, V.F. Alves, E.C. De Martinis, Unraveling microbial biofilms of importance for food microbiology. Microb. Ecol;vol. 68,pp.35-46,2014.

[6] C.Beloin, A .Roux, J.M. Ghigo, Escherichia coli biofilms. Curr. Top. Microbiol. Immunol;vol.322, PP.249-289,2008.

[7] A.Sulakvelidze, Z. Alavidze, J.G. Morris, Bacteriophage therapy. Antimicrob Agents Chemother, Vol.45,pp.649-59,2001.

[8] M.Kutateladze, R.Adamia, Bacteriophages as potential new therapeutics to replace or supplement antibiotics. Trends Biotechnol;vol. 28(12) , PP.591595,2010 .

[9] R.Smith, J.Coast ,The true cost of antimicrobial resistance. BMJ;vol.346, PP.14-93,2013.

[10] Z.Hosseinidoust, N. Tufenkji, T.G. van de Ven, Formation of biofilms under phage predation: considerations concerning a biofilm increase. Biofouling;vol. 29, PP.457-468,2013.

[11] J.Morris, N .Kelly, L. Elliott, A. Grant, M. Wilkinson, K. Hazratwala, P. McEwen, Evaluation of Bacteriophage Anti -Biofilm Activity for Potential Control of Orthopedic Implant Related Infections Caused by Staphylococcus Aureus. Surg Infect;vol. 20(1),pp.16-24,2019.

[12] McIntyre L, Hudson JA, Billington C, Withers H. Biocontrol of Foodborne Bacteria: Past, Present and Future Strategies. Food New Zeal., 2007; 7:25-32.

[13] U.Dissanayake, M .Ukhanova, Z.D. Moye, A. Sulakvelidze, V.Mai, Bacteriophages reduce pathogenic Escherichia coli counts in mice without distorting gut microbiota. Front. Microbiol;vol. 10, PP.19-84,2019.

[14] M.R. Clokie, A.D. Millard, A.V. Letarov, S.Heaphy ,Phages in nature. Bacteriophage;vol. 1, PP.3145,2011.

[15] Z.D.Moye, J .Woolston, A.Sulakvelidze ,Bacteriophage applications for food production and processing. Viruses ;vol. 10,pp.2-5,2018.

[16] International committee on microbiological specification on foods (ICMSF).. Microorganisms in foods: their significance and methods of enumeration. Univ. of Toronto, presses, Toronto and BuffaloCanada;vol.2 ,pp.15-12, 1978 
[17] B.D.Jett, K.L. Hatter, M.M. Huycke, M.S .Gilmore, Simplified agar plate method for quantifying viable bacteria. BioTechniques, Vol.23, PP.648-650,1997.

[18] G.D. Christensen, W.A. Simpson, J.J .Younger, L.M. Baddour, F.F. Barrett, D.M. Melton, E.Beachey ,Adherence of coagulase negative Staphylococci to plastic tissue culture plates: a quantitative model for the adherence of Staphylococci to medical devices. J. Clin. Microbiol, Vol.22,pp.996-1006,1985.

[19] D.R.Harper, H.M. Parracho, J. Walker, R. Sharp, G. Hughes, M .Werthén ,Bacteriophages and biofilms. Antibiotics;vol. 3, PP.270-284,2014.

[20] C.J. Sanchez Jr, K. Mende, M.L. Beckius , K.S. Akers, D.R. Romano, J.C. Wenke, C.K.Murray ,Biofilm formation by clinical isolates and the implications in chronic infections. BMC Infect. Dis;vol. 29, PP.13-47,2013.

[21] J.E. Cassat, M.S. Smeltzer, C.Y. Lee, Investigation of biofilm formation in clinical isolates of Staphylococcus aureus. Methods Mol Biol;vol.1085,pp.195-211,2014.

[22] S.Bose, M. Khodke, S. Basak, S.K. Mallick, Detection of biofilm producing Staphylococci: Need of the Hour. J Clin Diagn Res;vol. (3),pp.1915$1920,2009$.

[23] F.Zameer, M.S. Rukmangada, J.B. Chauhan, S.A. Khanum, P .Kumar, A.T. Devi, N. Prasad, M.N. Dhananjaya, Evaluation of adhesive and antiadhesive properties of Pseudomonas aeruginosa biofilms and its inhibition by herbal plants. Iran J Microbiol;vol. 8(2),pp.108-119,2016.

[24] D.J.Brenner, N.R. Krieg, J.T. Saley. Bergy"s manual of systematic bacteriology, part A (Introductory essays) USA-Springer, Vol.2,pp.2536,2005.

[25] A.W.Bauer, W.M. Kirby, J.C. Sherris, M. Turck , Antibiotic susceptibility testing by a standardized single disk method. Am J Clin Pathol;vol. 36,pp.493496,1966.

[26] CLSI (Clinical and Laboratory Standards Institute). Performance standards for antimicrobial susceptibility testing: twenty-first informational supplement. CLSI document CLSI, Wayne, PA;vol.5(3),pp.100- 21,2011.

[27] H.C.Chang, C.R. Chen, J.W. Lin, G.H .Shen, K.M. Chang, Y.H. Teseng, S.F. Weng, Isolation and characterization of novel giant Stenotrophomonas maltophilia phage phi SMA5. Appl. Environ. Microbiol;vol. 71, PP.1387-1393,2005.

[28] M.H.Adams, "Enumeration of bacteriophage particles," in The Bacteriophages, ed. M. H. Adams (New York, NY: Interscience publishers, Inc.) ;vol.88, pp.27-34,1959.

[29] M. Pajunen, S .Kiljunen, M.Skurnik ,Bacteriophage $\varphi \mathrm{YeO} 3-12$, Specific for Yersinia enterocolitica Serotype O:3, Is Related to Coliphages T3 and T7. J Bacteriol;vol. 182, PP.5114-5120,2000.

[30] W.J.Lee, C. Billingtion, J.A. Hudson, J.A. Heinemann, Isolation and characterization of phages infectiong Bacillus cereus. Lett. Appl. Microbiol;vol. 52, PP.456-464,2011.

[31] E.L. Ellis, M .Delbruck, The growth of bacteriophage. J. Gen. physiol, Vol.22(3) , PP.365384, 1939.

[32] K.Elhalag, M. Nasr-Eldin, A. Hussien, A.Ahmad, Potential use of soilborne lytic Podoviridae phage as a biocontrol agent against Ralstonia solanacearum. J. Basic Microbiol, Vol.58, PP.658-669,2018.

[33] J.H. Merritt, D.E. Kadouri, G.A. O'Toole, Growing and analyzing static biofilms. Curr. Protoc. Microbiol;vol.365,pp.125-654, 2005.

[34] M.Jamal, T. Hussain, C.R. Das, S.Andleeb ,Characterization of Siphoviridae phage $\mathrm{Z}$ and studying its efficacy against multidrug-resistant Klebsiella pneumonia planktonic cells and biofilm. J Med Microbiol;vol. 64, PP.454-462,2015.

[35] G.D.A. Wright, Antibiotic resistance: Where does it come from and what can we do about it? BMC Biol;vol. 8,pp.123,2010.

[36] N.Gundogan, O.Ataol ,Biofilm, protease and lipase properties and antibiotic resistance profiles of Staphylococci isolated from various foods. Afr. J. Microbiol. Res ;vol. 7(28), PP.3582-3588,2013.

[37] U. Römling, C. Balsalobre ,Biofilm infections, their resilience to therapy and innovative treatment strategies. J Intern Med;vol. 272,pp.541-561,2012.

[38] A.Wagih, G. Nanis, A .Maha, M.Afwat ,Antibacterial Response of Combination Between Antibiotics and Some Plant Extracts Against Multidrug Resistant Bacteria. Adv Biol Res, Vol.10 (1) , PP.51-57,2016.

[39] N. Allocati, M. Masulli, M.F. Alexeyev, C.Di Ilio, Escherichia coli in Europe: an overview. Int. J. Environ. Res. Public Health;vol. 10(12) , PP.6235$6254,2013$.

[40] W.D. Tanner, J.A. VanDerslice, R.K. Goel, M.K. Leecaster, M.A .Fisher, J. Olstadt, Multi-state study of Enterobacteriaceae harboring extended-spectrum beta-lactamase and carbapenemase genes in U.S. drinking water. Sci. Rep;vol. 9,pp.9-3938,2019.

[41] Y.Vuthy, K.S. Lay, H .Seiha, A. Kerleguer, A.Aidara-Kane, Antibiotic susceptibility and molecular characterization of resistance genes among Escherichia coli and among Salmonella subsp. in chicken food chains. Asian Pac J Trop Biomed, Vol.7,pp.670-674,2017.

[42] S. Srey, I.K. Jahid, S.Do Ha, Biofilm formation in food industries: A food safety concern. Food Control;vol. 31,pp.572-585,2013.

[43] R. Issa, N. Chanishvili, J. Caplin, E .Kakabadze, N. Bakuradze, K. Makalatia, I. Cooper ,Anti-Biofilm Potential of Purified Environmental Bacteriophage Preparations against Early Stage Pseudomonas aeruginosa Biofilms. J. Appl. Microbiol;vol. 126 (6), PP.1657-1667,2019.

[44] T.K. Lu, J.J. Collins, Dispersing biofilms with engineered enzymatic bacteriophage. Proc. Natl. Acad. Sci. USA, Vol.104, PP.11197-11202,2007. 
[45] H.Brussow, Phage therapy: The Escherichia coli experience. Microbiology; vol. 151(7) ,pp.21332140,2005 .

[46] Z.Lu, F .Breidt, V. Plengvidhya, H.P. Fleming, Bacteriophage ecology in commercial sauerkraut fermentations. Appl. Environ. Microbiol;vol. 69(6), PP.3192-3202,2003 .

[47] H.W. Ackermann,Phage classification and characterization. Methods in Molecular Biology ;vol.501, PP.127-140,2009.

[48] M.H. Ly-Chatain, The factors affecting effectiveness of treatment in phages therapy. Front Microbiol;vol.5, PP.51,2014.

[49] R.K. Shende, S.D. Hirpurkar, C. Sannat, N. Rawat, V. Pandey, Isolation and characterization of bacteriophages with lytic activity against common bacterial pathogens, Vet. World;vol. 10, PP.973$978,2017$.

[50] S.Shukla, S.D .Hirpurkar, Recovery status of bacteriophages of different livestock farms of Veterinary College, Adhartal, Jabalpur, India. Vet. World, Vol.4,pp.117-119,2011.

[51] J.Langlet, F. Gaboriaud, C. Gantzer, Effects of pH on plaque forming unit counts and aggregation of MS2 bacteriophage, J. Appl. Microbiol, Vol.103, PP.1632-1638,2007.

[52] P.F. Seaman, M.J. Day, Isolation and characterization of a bacteriophage with an unusually large genome from the Great Salt plains National wildlife Refuge, Oklahoma, USA. FEMS Microbiol Ecol, Vol.60, PP.1-13,2007.

[53] K.Ramirez, C. Cazarez-Montoya, H.S. LopezMoreno, N. Castro-Del Campo, Bacteriophage cocktail for biocontrol of Escherichia coli O157:H7: stability and potential allergenicity study. PLOS ONE; vol. 13, PP.195-23,2018.

[54] S.K .Jaiswal, B.Dhar ,Morphology and general characteristics of phages specific to Lens culinaris rhizobia. Biol. Fertil. Soil, Vol.46, PP.681-687,2010.

[55] W.F.Huff, G.R. Huff, N.C. Rath, J.M. Balog, A.M. Donoghue, Therapeutic efficacy of bacteriophage and Baytril (enrofloxacin) individually and in combination to treat colibacillosis in broilers. Poult Sci, Vol.83, PP.1944-1947,2004.
[56] P.Hyman, S.T. Abedon., "Bacteriophage host range and bacterial resistance," in Advances in Applied Microbiology, Vol. 70 eds Laskin A. I., Sariaslani S., Gadd G. M., editors. (San Diego: Elsevier Academic Press Inc;);vol.5(3), PP.217-248,2010.

[57] S.L.Díaz-Muñoz, B.Koskella ,Bacteria-phage interactions in natural environments. Adv Appl Microbiol, Vol.89,pp.135-83,2014.

[58] J.Uchiyama, M. Rashel, Y. Maeda, I .Takemura, S .Sugihara, K. Akechi, A .Muraoka, H .Wakiguchi, S.Matsuzaki ,Isolation and characterization of a novel Enterococcus faecalis bacteriophage EF24C as therapeutic candidate, FEMS Micropiol. Lett;vol. 278, PP.200-206,2008.

[59] M.K. Mirzaei, A.S. Nilsson, Isolation of phages for phage therapy: a comparison of spot tests and efficiency of plating analyses for determination of host rage and efficacy. PLOS ONE; vol. 10(5), PP.127-606,2015.

[60] P.Yu, J .Mathieu, M. Li, Z .Dai, P.J. Alvarez, Isolation of polyvalent bacteriophages by sequential multiple-host approaches. Appl. Environ. Microbiol, Vol.82, PP.808-815,2016.

[61] M.Park, J.H. Lee, H. Shin, M. Kim, J .Choi, D.H. Kang, S .Heu, S. Ryu, Characterization and comparative genomic analysis of a novel bacteriophage, SFP10, simultaneously inhibiting both Salmonella enterica and Escherichia coli O157:H7. Appl. Environ. Microbiol;vol. 78, PP.58-69,2012.

[62] B.R. Levin, J.J.Bull, Population and evolutionary dynamics of phage therapy, Nat. Rev. Microbiol, Vol.2, PP.166-173,2004.

[63] H.Shin, N. Bandara, E .Shin, S .Ryu, K.P. Kim, Prevalence of Bacillus cereus bacteriophages in fermented foods and characterization of phage. Res Microbiol;vol. 162, PP.791-797,2011.

[64] P.M.Sabour, M.W. Griffiths, Bacteriophages in the control of food and waterborne pathogens. ASM Press. Washington, DC,2010.

[65] S.Sagar, R. kumar, S.Kaistha, Inhibition of different stages of biofilm of Pseudomonas aeruginosa PA01 by isolated bacteriophage P2. J. Pharm, Clin. Res;vol. 8(2), PP.296-299,2015. 